\title{
Wide spread and diversity of mutation in the gyrA gene of quinolone-resistant Corynebacterium striatum strains isolated from three tertiary hospitals in China
}

Yingjun Wang ${ }^{1 \dagger}$, Xiaohong Shi ${ }^{2 \dagger}$, Jian Zhang ${ }^{3}$, Yanyan Wang ${ }^{1}$, Yingying Lv ${ }^{1}$, Xiaoli Du ${ }^{4}$, QiQiGe ChaoLuMen ${ }^{5 *}$ and Junrui Wang ${ }^{1 *}$

\begin{abstract}
Background: Corynebacterium striatum was confirmed to be an important opportunistic pathogen, which could lead to multiple-site infections and presented high prevalence of multidrug resistance, particularly to quinolone antibiotics. This study aimed to investigate the mechanism underlying resistance to quinolones and the epidemiological features of 410 quinolone-resistant C. striatum clinical strains isolated from three tertiary hospitals in China.

Methods: A total of 410 C. striatum clinical strains were isolated from different clinical samples of patients admitted to three tertiary teaching hospitals in China. Antibiotic susceptibility testing was performed using the microdilution broth method and pulsed-field gel electrophoresis (PFGE) was used for genotyping. Gene sequencing was used to identify possible mutations in the quinolone resistance-determining regions (QRDRs) of gyrA.

Results: In total, 410 C. striatum isolates were sensitive to vancomycin, linezolid, and daptomycin but resistant to ciprofloxacin. Depending on the antibiotic susceptibility testing results of 12 antimicrobial agents, the $410 \mathrm{C}$. striatum strains were classified into 12 resistant biotypes; of these, the three biotypes R1, R2, and R3 were dominant and accounted for $47.3 \%$ (194/410), 21.0\% (86/410), and 23.2\% (95/410) of the resistant biotypes, respectively. Mutations in the QRDRs ofgyrA were detected in all quinolone-resistant C. striatum isolates, and $97.3 \%$ of the isolates (399/410) showed double mutations in codons 87 and 91 of the QRDRs of gyrA. Ser-87 to Phe-87 and Asp-91 to Ala-91 double mutation in C. striatum was the most prevalent and accounted for $72.2 \%$ (296/410) of all mutations. Four new mutations in gyrA were identified in this study; these included Ser-87 to Tyr-87 and Asp-91 to Ala-91 (double mutation, 101 isolates); Ser-87 to Val-87 and Asp-91 toGly-91 (double mutation, one isolate); Ser-87 to Val-87 and Asp-91 to Ala-91 (double mutation, one isolate); and Ser-87 to lle-87 (single mutation, one isolate). The minimum inhibitory concentration of ciprofloxacin for isolates with double $(96.5 \%$; 385/399) and single $(72.7 \% ; 8 / 11)$ mutations was high $(\geq 32 \mu \mathrm{g} / \mathrm{mL}$ ). Based on the PFGE typing results, 101 randomly selected C. striatum strains were classified into 50 genotypes (T01-T50), including the three multidrug-resistant epidemic clones T02, T06, and T28; these accounted for
\end{abstract}

\footnotetext{
*Correspondence: chaolumenqi@126.com; wangjunrui123@yeah.net

'Yingjun Wang and Xiaohong Shi contributed equally to this work

1 Department of Laboratory Medicine, Affiliated Hospital of Inner

Mongolian Medical University, 010050 Hohhot, People's Republic of China

5 Pediatric Ward, Affiliated Hospital of Inner Mongolian Medical University,

010050 Hohhot, People's Republic of China

Full list of author information is available at the end of the article
} permits use, sharing, adaptation, distribution and reproduction in any medium or format, as long as you give appropriate credit to the original author(s) and the source, provide a link to the Creative Commons licence, and indicate if changes were made. The images or other third party material in this article are included in the article's Creative Commons licence, unless indicated otherwise in a credit line to the material. If material is not included in the article's Creative Commons licence and your intended use is not permitted by statutory regulation or exceeds the permitted use, you will need to obtain permission directly from the copyright holder. To view a copy of this licence, visit http://creativecommons.org/licenses/by/4.0/. The Creative Commons Public Domain Dedication waiver (http://creativeco mmons.org/publicdomain/zero/1.0/) applies to the data made available in this article, unless otherwise stated in a credit line to the data. 
14.9\% (15/101), 5.9\% (6/101), and 11.9\% (12/101) of all genotypes, respectively. The multidrug-resistant T02 clone was identified in hospitals A and C and persisted from 2016 to 2018. Three outbreaks resulting from the T02, T06, and T28 clones were observed among intensive care unit (ICU) patients in hospital C between April and May 2019.

Conclusions: Quinolone-resistant C. striatum isolates showed a high prevalence of multidrug resistance. Point mutations in the QRDRs of gyrA conferred quinolone resistance to C. striatum, and several mutations in gyrA were newly found in this study. The great clonal diversity, high-level quinolone resistance and increased prevalence among patients susceptible to C. striatum isolates deserve more attention in the future. Moreover, more thorough investigation of the relationship between quinolone exposure and resistance evolution in C. striatum is necessary.

Keywords: Corynebacterium striatum, Multi-drug resistance, Genotyping, Quinolone resistance, Nosocomial outbreak

\section{Background}

Recently, several reports have revealed that Corynebacterium striatum leads to multiple invasive infections [1, 2], and most C. striatum isolates are multidrug resistant, particularly to quinolones [3]. Point mutations in codons 87 and 91 in the quinolone resistance-determining regions (QRDRs) of $g y r A$ were believed to be majorly responsible for the resistance of $C$. striatum to quinolones [4]. Quinolones tend to accumulate in the organs, and the resistant subpopulations of some common genus of bacteria may be selected upon exposure to quinolones, including multiple kinds of bacteria that colonize the skin and mucous membranes (such as corynebacteria) [5].

Although a high frequency of $C$. striatum was recently reported in China, the mechanism underlying the resistance of $C$. striatum to quinolones has been rarely reported in China [6, 7]. In addition, quinolone consumption was observed to be high in many hospitals in the last decade [8]. Furthermore, the previous use of fluoroquinolones or beta-lactam antibiotics was believed to be an essential risk factor for promoting the colonization or infection of C. striatum [9]. C. striatum is known to colonize multiple environmental and bodily surfaces [10] and spread among susceptible patients or even lead to outbreaks, which were observed in previous studies [3, 11].

This study investigated the actual resistance mechanism of C. striatum to quinolones with a larger number of isolates collected from three tertiary hospitals in China and explored its genotypic characterization and prevalence potential.

\section{Methods}

\section{Isolation and identification of $C$. striatum}

The hospitals enrolled in this study included The Affiliated Hospital of Inner Mongolian Medical University (hospital A, 3,000 beds), Shandong Provincial QianFuoShan Hospital (hospital B, 2,813 beds), and Bayannaoer People's Hospital (hospital C, 1,700 beds), China, from March 2013 to May 2019. All C. striatum strains isolated from aseptic sites were identified. The quality of the sputum samples was evaluated for qualification based on the number of leukocytes and epithelium via microscopy [3], and the isolates collected from the qualified samples were enrolled in this study. All cultures suspected to be positive for $C$. striatum were routinely identified using VITEK-2 ANC card (BioMérieux, France) and stored at $-80{ }^{\circ} \mathrm{C}$. The isolates were further validated by MALDITOF microTyper (Tianrui, China) as well as $16 S$ rRNA and rpoB sequencing technique [12]. Only one C. striatum strain from the same patient was selected in this study, whereas the repeated ones were excluded.

\section{Antibiotic susceptibility test}

The antibiotic susceptibility test was performed using the broth microdilution method, and the antibiotics tested include penicillin $(1-64 \mu \mathrm{g} / \mathrm{mL})$, cefepime $(1-64 \mu \mathrm{g} /$ $\mathrm{mL})$, imipenem $(1-64 \mu \mathrm{g} / \mathrm{mL})$, linezolid $(0.5-4 \mu \mathrm{g} / \mathrm{mL})$, erythromycin $(0.5-64 \mu \mathrm{g} / \mathrm{mL})$, clindamycin $(1-32 \mu \mathrm{g} /$ $\mathrm{mL})$, gentamycin $(1-32 \mu \mathrm{g} / \mathrm{mL})$, tetracycline $(1-64 \mu \mathrm{g} /$ $\mathrm{mL})$, vancomycin $(0.5-4 \mu \mathrm{g} / \mathrm{mL})$, sulfamethoxazole $(0.5 / 9.5-8 / 152 \mu \mathrm{g} / \mathrm{mL})$, daptomycin $(0.06-1 \mu \mathrm{g} / \mathrm{mL})$, ciprofloxacin $(1-256 \mu \mathrm{g} / \mathrm{mL})$, and moxifloxacin $(0.06-32 \mu \mathrm{g} /$ $\mathrm{mL}$ ). The susceptibility test and result analysis were performed according to the 30th edition of the Clinical and Laboratory Standards Institute guidelines [13] and the recommendation of the European Committee on Antimicrobial Susceptibility Testing [14]. Streptococcus pneumoniae ATCC 49619 was used as the control.

\section{Pulsed-field gel electrophoresis (PFGE)}

The bacterial density of the tested C. striatum isolates was adjusted to 3.5-4.0 Mcf and digested with lysostaphin $(1 \mathrm{mg} / \mathrm{ml})\left(\right.$ Merck, USA) at $37^{\circ} \mathrm{C}$ for $30 \mathrm{~min}$. The bacterial chromosomal DNA of the isolates was extracted and cleaved using $40 \mathrm{U}$ SwaI (Takara, China). The DNA of the S. Braenderup H9812 standard strain was extracted and cleaved using $40 \mathrm{U} \mathrm{XbaI} \mathrm{(Takara,} \mathrm{China)} \mathrm{and} \mathrm{utilized}$ as the molecular mass standard. Electrophoresis was performed on the CHEF-Mapper XA PFGE system (BioRad, Hercules, CA, USA), and PFGE profiles were analyzed using the Bionumerics v.7.6 software. The isolates 
with $100 \%$ similarity were considered indistinguishable $[15,16]$, and each clone was named using a single capital letter.

\section{Detection of mutation in the QRDR region of $g y r A$}

The bacterial chromosomal DNA of the tested S. aureus isolates was extracted as per the instructions of the TIANamp Bacterial DNA kit (Tiangen Biotech, China). The pair of primers used for polymerase chain reaction (PCR) amplification and sequencing were Coryn-1 (GCG GCT ACG TAA AGT CC) and Coryn-2 (CCG CCG GAGCCG TTC AT). For PCR amplification, the protocol detailed by Sierra et al. was followed [5]. The PCR products were sequenced with the same primers as those used in PCR amplification on ABI 3730XL DNA Analyzer (Applied Biosystems, USA). Additionally, the sequence of C. striatum ATCC6940 was used as the control for sequence comparison among different clinical C. striatum isolates.

\section{Results}

\section{Characterization of the isolates}

From the 410 isolates analyzed in this study, 77.8\% (319/410) were collected from hospital A, 10.0\% (41/410) from hospital B, and 12.2\% (50/410) from hospital C. Most of the C. striatum strains $(88.3 \% ; 362 / 410)$ were isolated from sputum (Table 1). The average age of the patients was 63 years, and male and female patients accounted for $71.2 \%(292 / 410)$ and $28.8 \%$ (118/410), respectively.

\section{Antibiotic susceptibility testing}

The antibiotic susceptibility testing results showed that all strains were sensitive to vancomycin, linezolid, and daptomycin and resistant to penicillin, cefepime, ciprofloxacin, and moxifloxacin. The total resistance rates of 410 C. striatum isolates to imipenem, erythromycin, clindamycin, tetracycline, gentamycin, sulfamethoxazole, and trimethoprim were 90.7\% (372/410), 98.8 (405/410), 98.5 (404/410), 70.5 (289/410), 53.2 (218/410), and 98.0 (402/410), respectively (Table 2 ).

Based on the susceptibility testing results, 410 C. striatum strains can be classified into 12 resistance biotypes, designated as patterns R1-R12. Among the isolotes, those with resistance to erythromycin, clindamycin, imipenem, tetracycline, and gentamycin were classified to be nonsusceptible as they were resistant or intermediate to the five types of antibiotics tested in this study. Among these, three dominant biotypes (R1, R2, and R3) were identified, which were resistant or intermediate to most antibiotics tested in this study, except for vancomycin, linezolid, and daptomycin. The resistance features of the 12 resistant biotypes diversely changed (Table 3 ). In total,
Table 1 Demographic and clinical features of patients $(n=410)$

\begin{tabular}{lc}
\hline Variable & Number (\%) \\
\hline Age (years) & $6.6(27 / 410)$ \\
$<40$ & $33.4(137 / 410)$ \\
$40-59$ & $44.1(181 / 410)$ \\
$60-79$ & $15.9(65 / 410)$ \\
$\geq 80$ & \\
Gender & $28.8(118 / 410)$ \\
Female & $71.2(292 / 410)$ \\
Male & \\
Specimens & $88.3(362 / 410)$ \\
Sputum & $4.1(17 / 410)$ \\
Wound discharge & $1.5(6 / 410)$ \\
BALF & $1.2(5 / 410)$ \\
Whole blood & $1.0(4 / 410)$ \\
Pus & $0.7(3 / 410)$ \\
Urine & $0.7(3 / 410)$ \\
Central venous catheters & $0.7(3 / 410)$ \\
Nasopharyngeal swab & $0.7(3 / 410)$ \\
Drainage & $0.5(2 / 410)$ \\
Hydrothorax and ascites & $0.5(2 / 410)$ \\
Cerebrospinal fluid &
\end{tabular}

$B A L F$ Bronchoalveolar lavage fluid

319 isolates collected from hospital A belonged to 12 resistance biotypes, and most of the isolates belonged to R1 (46.1\%; 147/319), R2 (24.5\%; 78/319), and R3 (23.5\%; $75 / 319)$. In addition, 41 isolates collected from hospital $\mathrm{B}$ were divided into eight resistance biotypes, and $56.1 \%$ (23/41) and $17.1 \%$ of the isolates (7/41) belonged to R1 and R2, respectively. Finally, 50 isolates collected from hospital $\mathrm{C}$ were classified into four resistance biotypes, and $48.0 \%(24 / 50)$ and $36.0 \%$ of the isolates $(18 / 50)$ belonged to R1 and R3, respectively.

\section{Gene sequencing}

Single-site and double-site mutations within the QRDRs of gyrA were observed among all 410 C. striatum strains, and eight mutations were observed in this study (Table 4). All isolates showed mutations in codon $87 ; 97.3 \%$ of the isolates $(399 / 410)$ had double mutations in codons 87 and 91 , whereas only $2.7 \%$ isolates $(11 / 410)$ had a single mutation in codon 87 . Ser- 87 to Phe- 87 and Asp-91 to Ala-91 double mutations in C. striatum accounted for $72.2 \%(296 / 410)$ of the isolates. Meanwhile, four new mutations in $g y r A$ were found in this study, including Ser-87 to Tyr-87 and Asp-91 to Ala-91 (double mutation, 101 isolates), Ser-87 to Val-87 and Asp-91 to Gly91 (double mutation, one isolate), Ser-87 to Val-87 and Asp-91 to Ala-91 (double mutation, one isolate), and Ser87 to Ile-87 (single mutation, one isolate). Isolates with 
Table 2 Antibiotics susceptibility profiles of 410 C. striatum strains

\begin{tabular}{|c|c|c|c|c|}
\hline \multirow[t]{2}{*}{ Antibiotics } & \multicolumn{3}{|c|}{$\mathrm{MIC}(\mu \mathrm{g} / \mathrm{ml})$} & \multirow{2}{*}{$\begin{array}{l}\text { Percentage of } \\
\text { resistant isolates, \% } \\
\text { (n/410) }\end{array}$} \\
\hline & $\mathrm{MIC}_{50}$ & $\mathrm{MIC}_{90}$ & Range & \\
\hline Penicillin & $\geq 8$ & $>64$ & $\leq 1, \geq 4$ & $100(410 / 410)$ \\
\hline Cefepime & $\geq 8$ & $>64$ & $\leq 1, \geq 4$ & $100(410 / 410)$ \\
\hline Imipenem & $\geq 32$ & $>64$ & $\leq 4, \geq 16$ & $90.7(372 / 410)$ \\
\hline Ciprofloxacin & $\geq 32$ & 64 & $\leq 1, \geq 4$ & $100.0(410 / 410)$ \\
\hline Moxifloxacin & 8 & 16 & $\leq 0.5,>0.5$ & $100.0(410 / 410)^{\mathrm{a}}$ \\
\hline Erythromycin & 32 & 64 & $\leq 0.5, \geq 2$ & $98.8(405 / 410)$ \\
\hline Clindamycin & 16 & $>32$ & $\leq 0.5, \geq 4$ & $98.5(404 / 410)$ \\
\hline Tetracycline & $\geq 32$ & $>64$ & $\leq 4, \geq 16$ & $70.5(289 / 410)$ \\
\hline Gentamycin & 8 & $\geq 32$ & $\leq 4, \geq 16$ & $53.2(218 / 410)$ \\
\hline $\begin{array}{l}\text { Sulfamethoxazole and trimetho- } \\
\text { prim }\end{array}$ & $\geq 8 / 152$ & $\geq 8 / 152$ & $\leq 2 / 38, \geq 4 / 76$ & $98.0(402 / 410)$ \\
\hline Linezolid & $<0.5$ & $<0.5$ & $\leq 2$ & $0(0.0)$ \\
\hline Daptomycin & $<0.5$ & $<0.5$ & $\leq 1$ & $0(0.0)$ \\
\hline Vancomycin & $<0.5$ & $<0.5$ & $\leq 2$ & $0(0.0)$ \\
\hline
\end{tabular}

${ }^{a}$ Based on EUCAST breakpoint for Corynebacterium spp

Table 3 Resistance biotypes of 410 C. striatum strains

\begin{tabular}{|c|c|c|c|c|c|c|c|c|c|c|c|c|c|}
\hline \multirow{2}{*}{$\begin{array}{l}\text { Resistance } \\
\text { biotypes }\end{array}$} & \multirow{2}{*}{$\begin{array}{l}\text { No. of } \\
\text { Isolates (n) }\end{array}$} & \multicolumn{12}{|c|}{ Antibiotics } \\
\hline & & VAN & DAP & LNZ & $P$ & FEP & CIP & SXT & $E$ & CLI & IPM & TE & GEN \\
\hline $\mathrm{R} 1$ & 194 & $\mathrm{~S}$ & S & $\mathrm{S}$ & $\mathrm{R}$ & $\mathrm{R}$ & $\mathrm{R}$ & $\mathrm{R}$ & $\mathrm{R}$ & I/R & I/R & I/R & I/R \\
\hline $\mathrm{R} 2$ & 86 & $\mathrm{~S}$ & $\mathrm{~S}$ & $\mathrm{~S}$ & $\mathrm{R}$ & $\mathrm{R}$ & $\mathrm{R}$ & $\mathrm{R}$ & $\mathrm{R}$ & I/R & $\mathrm{R}$ & I/R & S \\
\hline R3 & 95 & S & S & S & $\mathrm{R}$ & $\mathrm{R}$ & $\mathrm{R}$ & $\mathrm{R}$ & $\mathrm{R}$ & $\mathrm{R}$ & $\mathrm{I} / \mathrm{R}$ & S & I/R \\
\hline $\mathrm{R} 4$ & 17 & $\mathrm{~S}$ & S & $\mathrm{S}$ & $\mathrm{R}$ & $\mathrm{R}$ & $\mathrm{R}$ & $\mathrm{R}$ & $\mathrm{R}$ & $\mathrm{R}$ & $\mathrm{S}$ & $\mathrm{R}$ & $\mathrm{R}$ \\
\hline R5 & 6 & $\mathrm{~S}$ & S & $S$ & $\mathrm{R}$ & $\mathrm{R}$ & $\mathrm{R}$ & $\mathrm{R}$ & I/R & $\mathrm{R}$ & $\mathrm{R}$ & $\mathrm{S}$ & S \\
\hline R6 & 2 & $\mathrm{~S}$ & $\mathrm{~S}$ & $\mathrm{~S}$ & $\mathrm{R}$ & $\mathrm{R}$ & $\mathrm{R}$ & $\mathrm{S}$ & $\mathrm{R}$ & I/R & $\mathrm{R}$ & $\mathrm{S}$ & $\mathrm{S}$ \\
\hline R7 & 2 & $S$ & $S$ & $S$ & $\mathrm{R}$ & $\mathrm{R}$ & $\mathrm{R}$ & $S$ & $\mathrm{R}$ & $\mathrm{R}$ & $\mathrm{R}$ & $\mathrm{R}$ & 1 \\
\hline R8 & 2 & $S$ & $S$ & $S$ & $\mathrm{R}$ & $\mathrm{R}$ & $\mathrm{R}$ & $S$ & $\mathrm{R}$ & $\mathrm{R}$ & $\mathrm{R}$ & $\mathrm{R}$ & $\mathrm{S}$ \\
\hline R9 & 2 & $S$ & $S$ & $S$ & $\mathrm{R}$ & $\mathrm{R}$ & $\mathrm{R}$ & $\mathrm{R}$ & $S$ & $S$ & $\mathrm{R}$ & I/R & $S$ \\
\hline R10 & 2 & $S$ & $S$ & $S$ & $\mathrm{R}$ & $\mathrm{R}$ & $\mathrm{R}$ & $S$ & $\mathrm{R}$ & $\mathrm{R}$ & $\mathrm{R}$ & $S$ & 1 \\
\hline $\mathrm{R} 11$ & 1 & $S$ & $S$ & $S$ & $\mathrm{R}$ & $\mathrm{R}$ & $\mathrm{R}$ & $\mathrm{R}$ & $S$ & $\mathrm{R}$ & $\mathrm{R}$ & $\mathrm{R}$ & $\mathrm{R}$ \\
\hline $\mathrm{R} 12$ & 1 & $S$ & $S$ & $S$ & $\mathrm{R}$ & $\mathrm{R}$ & $\mathrm{R}$ & $R$ & $R$ & $R$ & $S$ & $S$ & $R$ \\
\hline
\end{tabular}

VAN vancomycin, DAP daptomycin, $L N Z$ linezolid, $P$ penicillin, FEP cefepime, CIP ciprofloxacin, $S X T$ sulfamethoxazole and trimethoprim, $E$ erythromycin, $C L I$ clindamycin, IPM imipenem, TE tetracycline, GEN gentamycin

double mutations (96.5\%; 385/399) in gyrA showed high minimum inhibitory concentration (MIC) of $\geq 32 \mu \mathrm{g} / \mathrm{mL}$ to ciprofloxacin, whereas $72.7 \%(8 / 11)$ of the C. striatum strains with a single mutation in $g y r A$ presented with high MIC of $\geq 32 \mu \mathrm{g} / \mathrm{mL}$ to ciprofloxacin. For five quinolone-sensitive $C$. striatum clinical isolates collected in this study, no mutation in gyrA was identified.

\section{PFGE}

A total of 101 C. striatum strains with different resistance biotypes were randomly selected for PFGE typing, and 50 PFGE types were identified, among which types
T02 (15 isolates), T06 (6 isolates), and T28 (12 isolates) were dominant clones that accounted for $14.9 \%$ (15/101), $5.9 \%(6 / 101)$, and $11.9 \%(12 / 101)$, respectively. The isolates belonged to the clones with similar antibiotic resistance features and were multidrug resistant. These three clones were mainly isolated from patients admitted to the neurosurgery unit and intensive care unit (ICU) (Fig. 1). The T02 clone prevailed in hospital A $(40.00 \% ; 6 / 15)$ and hospital C (60.00\%; 9/15), whereas the T06 and T28 clones were only isolated from the patients admitted to hospital C (18/18; 100.0\%). The T02 clone showed a longterm persistence in hospital A from 2016 to 2018, and 
Table 4 Mutation modes of QRDR region in gyrA gene among 410 C. striatum isolates

\begin{tabular}{|c|c|c|}
\hline \multirow[t]{2}{*}{ No. of isolates } & \multicolumn{2}{|c|}{ Mutations of QRDRs within gyrA gene } \\
\hline & Codon 87 & Codon 91 \\
\hline 296 & $S($ Ser $) \rightarrow F($ Phe) & $\mathrm{D}(\mathrm{Asp}) \rightarrow \mathrm{A}(\mathrm{Ala})$ \\
\hline 101 & $\mathrm{~S}(\mathrm{Ser}) \rightarrow \mathrm{Y}(\mathrm{Tyr})$ & $\mathrm{D}(\mathrm{Asp}) \rightarrow \mathrm{A}(\mathrm{Ala})$ \\
\hline 1 & $\mathrm{~S}(\mathrm{Ser}) \rightarrow \mathrm{F}$ (Phe) & - \\
\hline 4 & $\mathrm{~S}(\mathrm{Ser}) \rightarrow \mathrm{V}(\mathrm{Val})$ & - \\
\hline 5 & $S($ Ser $) \rightarrow Y(T y r)$ & - \\
\hline 1 & $S($ Ser $) \rightarrow$ I (lle) & - \\
\hline 1 & $\mathrm{~S}(\mathrm{Ser}) \rightarrow \mathrm{V}(\mathrm{Val})$ & $D($ Asp) $\rightarrow G(G l y)$ \\
\hline 1 & $\mathrm{~S}(\mathrm{Ser}) \rightarrow \mathrm{V}(\mathrm{Val})$ & $\mathrm{D}(\mathrm{Asp}) \rightarrow \mathrm{A}(\mathrm{Ala})$ \\
\hline
\end{tabular}

an outbreak was observed in the ICU of hospital C from May 12 to May 19, 2019. The other two outbreaks of the T06 and T28 clones also emerged in the ICU of hospital C from April to May 2019 (Fig. 2). Furthermore, three dominant clones showed high levels of ciprofloxacin or moxifloxacin resistance, and the MICs of moxifloxacin of all isolates were significantly lower than those of ciprofloxacin. The moxifloxacin MIC of the C. striatum strains belonging to the T02 clones was $\geq 8 \mu \mathrm{g} / \mathrm{mL}$, which was higher than that of the strains belonging to the T06 and T28 clones. Double mutations in codons $87(\mathrm{~S} \rightarrow \mathrm{F} / \mathrm{Y})$ and $91(\mathrm{D} \rightarrow \mathrm{A})$ of $\operatorname{gyr} A$ were identified in these three dominant clones (Table 5).

In the three nosocomial outbreaks caused by the three clones of $C$. striatum, 33 patients were involved and $12.1 \%(4 / 33)$ of the patients died. The average age of patients and length of hospital stay were 58 years and $30 \mathrm{~d}$, respectively. Moreover, $97 \%$ (32/33) of the patients were exposed to different antibiotics 2 weeks before $C$. striatum isolation, and most of these patients had different comorbidities, including cerebrovascular events (39.4\%; 13/33), chronic obstructive pulmonary disease (36.4\%; 12/33), and malignant diseases $(21.1 \% ; 7 / 33)$ (Table 6).

\section{Discussion}

\section{Resistance features of $C$. striatum isolates}

In this study, most of the 410 C. Striatum strains were isolated from lower respiratory tract samples (93.2\%; 382/410). Meanwhile, five C. striatum strains were isolated from whole blood samples and one strain was repeatedly isolated from an immunosuppressed patient with infective endocarditis. Consistent with the results of previous investigations $[6,16]$, the $C$. striatum strains detected in this study were sensitive to vancomycin and linezolid. By contrast, all isolates were ciprofloxacin-resistant, and most had high MICs $(\geq 32 \mu \mathrm{g} / \mathrm{mL})$ to ciprofloxacin. Three dominant resistance biotypes were identified in this study, which accounted for $91.5 \%$ (375/410), and the strains were resistant to penicillin, cefepime, ciprofloxacin, and erythromycin. Although the isolates from the three hospitals were categorized into 12 resistant biotypes, no significant difference in geographical distribution was observed. Daptomycin resistance in C. striatum has been reported in previous studies [17, 18]; however, no daptomycin-resistant isolate was identified in this present study.

\section{Mechanism of quinolone resistance in C. striatum isolates}

The level of quinolone resistance depended on the type of amino substitution; isolates with double mutations on codons 87 and 91 showed a higher level of quinolone resistance than those with a single mutation on codon 87 [5, 16]. In this study, most of the quinolone-resistant C. striatum isolates were confirmed to have double mutations in gyrA (codons 87 and 91). However, not all isolates presented with MIC of $\geq 32 \mu \mathrm{g} / \mathrm{mL}$ to ciprofloxacin. By contrast, a single mutation in gyrA (codon 87) was detected in 11 C. striatum isolates, and the MICs of $72.7 \%(8 / 11)$ isolates to ciprofloxacin were $\geq 32 \mu \mathrm{g} /$ $\mathrm{mL}$. The significant relationship between amino mutation patterns and resistance levels to quinolones was not observed in this study. Furthermore, four new mutation patterns in C. striatum were found in this study, including three double mutations in codons 87 and 91 of $\mathrm{gyr} A$ and a single mutation in codon 87 of $g y r A$. Two kinds of new mutations, the double mutation pattern $(87-\mathrm{S} \rightarrow \mathrm{Y}$, $91-\mathrm{D} \rightarrow \mathrm{A})$ and the single mutation pattern $(87-\mathrm{S} \rightarrow \mathrm{I})$, were previously found in C. urealyticum and C. jeikeium [4]. To the best of our knowledge, the remaining two types of newly detected mutation patterns in C. striatum have not been reported previously, which had double mutations in codon 87 and 91. In particular, isolates with the double mutation pattern $(87-\mathrm{S} \rightarrow \mathrm{Y}, 91-\mathrm{D} \rightarrow \mathrm{A})$ accounted for $24.6 \%$ (101/410). Further, Sierra et al. [5] found that some $C$. striatum strains with a single mutation in codon 87 were ciprofloxacin-resistant but sensitive to moxifloxacin, suggesting that other resistance mechanisms contribute to moxifloxacin resistance in $C$. striatum. However, no moxifloxacin-sensitive strain was detected in this study, and a higher level of resistance of C. striatum to moxifloxacin was observed. The $\mathrm{MIC}_{90}$ of the 410 C. striatum isolates to moxifloxacin was high, i.e., up to $8 \mu \mathrm{g} / \mathrm{mL}$, indicating severe quinolone resistance in C. striatum in these hospitals. Unfortunately, quinolones appear to exert double effects on C. striatum, which could both induce its resistance to quinolones and promote $C$. striatum acquisition among susceptible patients $[3,9]$. Cumulatively, preventing quinolone exposure appears to be the most efficient way to control $C$. 


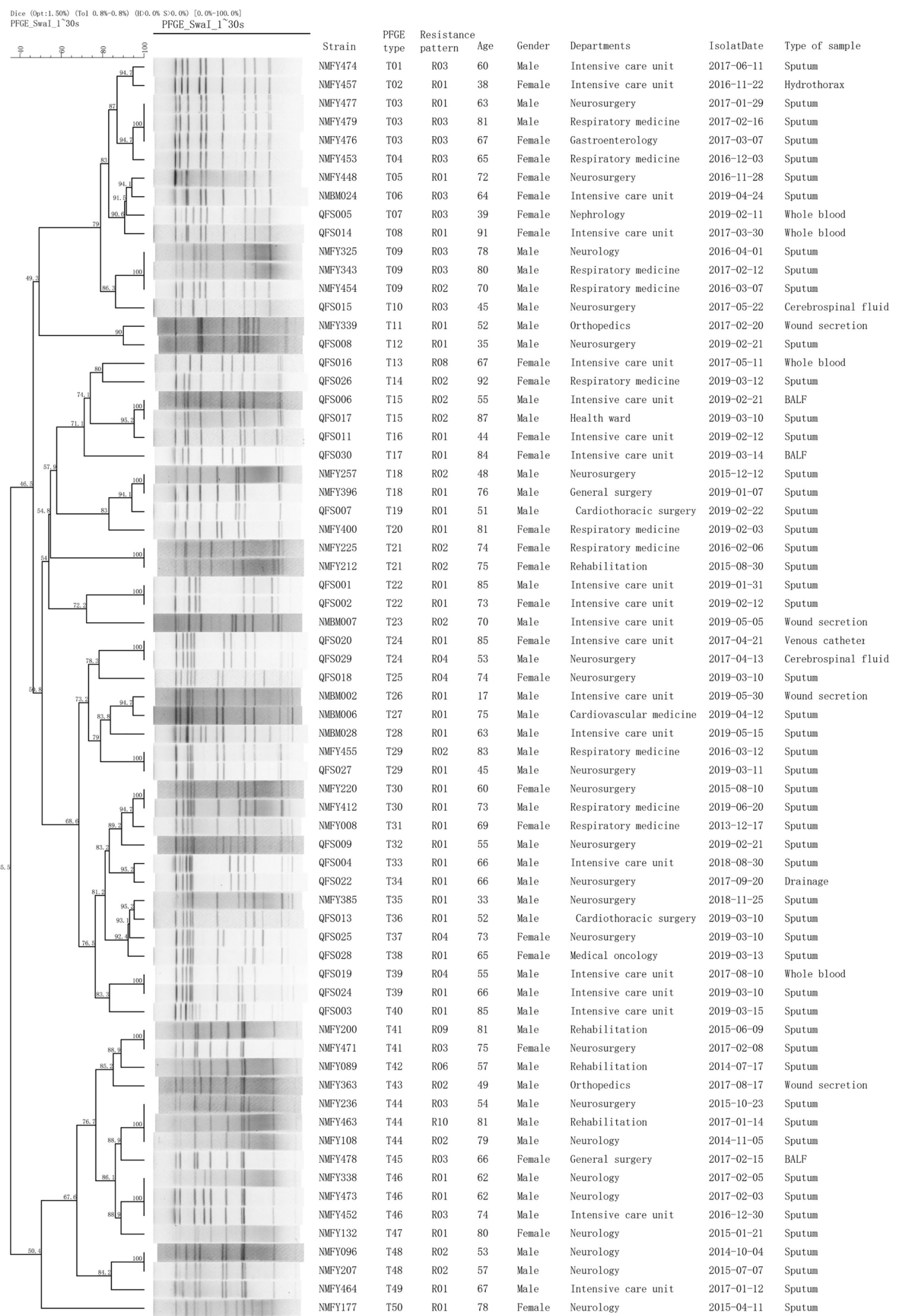

Fig. 1 Molecular characterization of 101 C. striatum strains with different resistance biotypes. For each types of T02, T06, T20 and T27, only the PFGE gel of one representative isolate were presented here. T02 clone, T06 clone, T20 clone, and T27 clone were composed by 12, 6, 4 and 15 isolates, respectively 


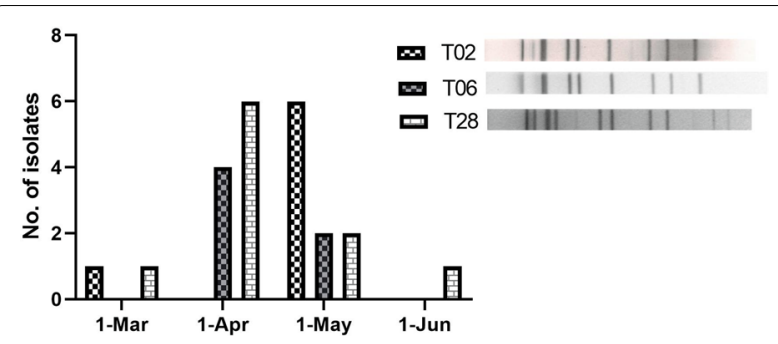

Fig. 2 Prevalence of three dominant clones (T02, T06 and T27) among the patients admitted to ICU during March to June, 2019 in hospital C

striatum infection or prevent the development of resistance to quinolones.

\section{Relationship between PFGE typing and antimicrobial resistance}

To further verify whether some dominant clones could prevail in a hospital environment, the PFGE typing method was employed, which is considered the gold standard method for the epidemiological investigation of important hospital-acquired bacterial pathogens [19]. A previous study revealed that the multidrug resistance phenotype of C. striatum is associated with specific PFGE types [20]. However, another study presented controversial results that the resistance phenotype was not related to specific clones [9], consistent with the findings of this present study. Because most of the strains detected in this study were multidrug resistant, the corresponding relationship between the PFGE genotypes and resistance biotypes could not be identified based on the study results.

\section{Nosocomial transmission of the dominant C. striatum clones}

Consistent with the findings of this study, Baio et al. [20] reported that some dominant $C$. striatum clones could rapidly spread among inpatients and that $C$. striatum could transmit from person to person via healthcare personnel or the medical environment $[21,22]$. Three dominant clones were identified in this study, which persisted in the several wards of hospital A from 2016 to 2018. This suggests a strong fitness ability of C. striatum among susceptible patients within the hospital environment. Unfortunately, based on the current data, it was difficult to confirm whether the dominant clones belonged to the same origin in these three hospitals as they are located at long distances. Further, three outbreaks were observed among patients admitted to the ICU of hospital C in 2019, resulting from the T02, T06, and T28 clones, respectively. Of note, the three clones coexisted among different patients in the ICU of hospital $\mathrm{C}$ from April to June 2019, indicating a multisource feature and rapid spread of $C$. striatum. Therefore, more efficient measures for infection control should be implemented to better controlling the transmission of C. striatum. Moreover, 33 patients were confirmed to be involved in these three nosocomial outbreaks; most of these patients had at least one comorbidity and 97\% (32/33) were exposed to at least one broad-spectrum antibiotic 2 weeks before C. striatum isolation. This finding implies that for special hospital units with critically ill patients, more attention should be paid when $C$. striatum strains are isolated.

A recent report revealed that some dominant $C$. striatum clones showed resistance to some widely used biocides at different levels, including high-level disinfectants (such as glutaraldehyde) [23]. Therefore, the sensitivity of dominant C. striatum isolates from different hospitals to commonly used biocides should be further evaluated, and the selective use of effective biocides should be considered. In this study, 50 PFGE genotypes were identified among 101 C. striatum isolates, and high genotyping diversity was observed in the strains isolated from the same hospital, particularly those isolated from hospitals $\mathrm{A}$ and $\mathrm{B}$. This suggests that multidrug $C$. striatum isolates originate from diverse origins and more dominant clones are selected under suitable circumstances, such as an increasing number of susceptible patients and nonrational application of broad-spectrum antibiotics.

\section{Limitations}

The limitations of this study are indicated as follows. Only 101 C. striatum isolates were genotyped using the PFGE method owing to the limitation of the expenditure.

Table 5 Characterization of quinolone resistance of three dominant C. striatum clones

\begin{tabular}{|c|c|c|c|c|c|c|}
\hline \multirow[t]{2}{*}{ Clones } & \multicolumn{2}{|c|}{ Ciprofloxacin ( $\mu \mathrm{g} / \mathrm{mL})$} & \multicolumn{2}{|c|}{ Moxifloxacin $(\mu \mathrm{g} / \mathrm{mL})$} & \multicolumn{2}{|c|}{$\begin{array}{l}\text { Sequence of gyrA gene } \\
\text { (aa) }\end{array}$} \\
\hline & MICs & Sensivity $(\leq 1, \geq 4)$ & MICs & Sensivity $(\leq 0.5,>0.5)$ & $87-5$ & 91-D \\
\hline $\mathrm{T} 28$ & $\geq 32$ & $\mathrm{R}$ & $\geq 4$ & $\mathrm{R}$ & F & A \\
\hline T06 & $\geq 32$ & $\mathrm{R}$ & $\geq 4$ & $\mathrm{R}$ & Y & A \\
\hline T02 & $\geq 32$ & $\mathrm{R}$ & $\geq 8$ & $\mathrm{R}$ & Y & A \\
\hline
\end{tabular}


Table 6 Descriptive characteristics of 33 patients involved in three nosocomial outbreaks

\begin{tabular}{lc}
\hline Variable & Number (\%) \\
\hline Length of hospital stay (days) & \\
$\leq 7$ & $6.1(2 / 33)$ \\
$8-14$ & $9.1(3 / 33)$ \\
$15-21$ & $24.2(8 / 33)$ \\
$>21$ & $60.6(20 / 33)$ \\
Age (years) & \\
$<40$ & $6.1(2 / 33)$ \\
$40-59$ & $33.3(11 / 33)$ \\
$60-79$ & $51.5(17 / 33)$ \\
$\geq 80$ & $9.1(3 / 33)$ \\
Outcome of the patients & \\
Death & $12.1(4 / 33)$ \\
Antibiotic intake & \\
Cephalosporins & $42.4(14 / 33)$ \\
Carbapenem & $24.2(8 / 33)$ \\
$\beta$-lactam/ $\beta$-lactamase inhibitor combinations & $36.4(12 / 33)$ \\
Quinolones & $15.2(5 / 33)$ \\
Glycopeptides & $12.1(4 / 33)$ \\
Aminoglycosides & $0(0 / 33)$ \\
Macrolides & $0(0 / 33)$ \\
Lincosamides & $0(0 / 33)$ \\
Trimethoprim-Sulfamethoxazole & $0(0 / 33)$ \\
Comorbid diseases & \\
Cerebrovascular event & $39.4(13 / 33)$ \\
Chronic obstructive pulmonary disease & $36.4(12 / 33)$ \\
Malignant diseases & $21.1(7 / 33)$ \\
Diabetes mellitus & $6.1(3 / 33)$ \\
Chronic renal failure & $3.0(1 / 33)$ \\
Heart failure & \\
\hline & \\
\hline &
\end{tabular}

${ }^{a}$ The antibiotic intake was calculated within two weeks before C. striatum isolation

The actual classification and distribution of different clones among different wards or patients may lack accuracy owing to selection bias. Therefore, dominant clones and nosocomial outbreaks may have been underestimated based on these data. Furthermore, a limited number of isolates were obtained from hospitals $B$ and $C$, and only the isolates from 2019 were eventually analyzed in this study. Therefore, the actual resistant phenotypes of C. striatum isolates and prevalence potential of dominant clones within these two hospitals need to be further explored.

\section{Conclusions}

Most C. striatum clinical strains analyzed in this study showed multidrug resistance, particularly to quinolones. The diversity of mutation in the gyrA of C. striatum is reported for the first time in this study. The strict restriction of quinolone use and prevention of its selective pressure on $C$. striatum may be the most effective way to minimize $C$. striatum colonization or infection and suppress the development of its resistance to quinolones. Dominant clones should be paid more attention in future infection control strategies as they can persist in hospitals for a long period and widely spread among susceptible patients.

\section{Abbreviations \\ QRDRs: Quinolone Resistance-Determining Regions; PFGE: Pulsed-field gel electrophoresis; PCR: Polymerase chain reaction; MIC: Minimum inhibitory concentration; ICU: Intensive care unit. \\ Acknowledgements \\ We thank all Lab Medicine Department staff for assisting with isolates storage.}

\section{Authors' contributions}

JW and QC are responsible for design of this study, data analysis, manuscript draft and check. YW is responsible for experiment of gene sequencing and data analysis. XS, JZ are responsible for strains isolation and identification. YW is responsible for antibiotics susceptibility testing. XD is responsible for PFGE are responsible for molecular experiments and data analysis. GC is responsible for data analysis, manuscript draft and check. All authors read and approved the final manuscript.

\section{Funding}

This study is supported by Major project of Affiliated hospital of Inner Mongolia Medical University (NYFY ZD 012), Science and Technology Research Plan Program in Inner Mongolian Autonomous Region (No.YS2019150005) and Natural Science Foundation of Inner Mongolia Autonomous Region of China (No. 2017MS08889).

\section{Availability of data and materials \\ None.}

\section{Declarations}

Ethics approval and consent to participate

This work is exempt from formal ethical approval and informed consent according to the local ethical guidelines, and was approved by Ethics committee of Affiliated hospital of Inner Mongolian medical university (Reference number KY2020029).

\section{Consent for publication}

No individual person's data was included in this study, and consent for publication is not required.

\section{Competing interests}

The authors declare that they have no competing interests.

\section{Author details}

${ }^{1}$ Department of Laboratory Medicine, Affiliated Hospital of Inner Mongolian Medical University, 010050 Hohhot, People's Republic of China. ${ }^{2}$ Department of Clinical Laboratory Medicine, The First Affiliated Hospital of Shandong First Medical University \& Shandong Provincial Qianfoshan Hospital, Shandong Medicine and Health Key Laboratory of Laboratory Medicine, 250014 Jinan, People's Republic of China. ${ }^{3}$ Department of Laboratory Medicine, Bayannur People's Hospital, 015000 Bayannur, People's Republic of China. ${ }^{4}$ National Institute for Communicable Disease Control and Prevention, Chinese Center for Disease Control and Prevention, 102206 Beijing, People's Republic of China. ${ }^{5}$ Pediatric Ward, Affiliated Hospital of Inner Mongolian Medical University, 010050 Hohhot, People's Republic of China.

Received: 3 April 2021 Accepted: 26 September 2021 Published online: 01 October 2021 


\section{References}

1. Naqvi SY, Salama IG, Narins C, Stuver T. Corynebacterium striatum prosthetic valve endocarditis with severe aortic regurgitation successfully treated with transcatheter aortic valve replacement. BMJ Case Rep. 2018;11:e226881.

2. Yang HS, Kim YJ, Cho SY, Shin E, Lee HJ. Central venous catheter-related bloodstream infection by Corynebacterium striatum identified by $16 \mathrm{~S}$ rRNA and rpoB gene sequencing. Ann Lab Med. 2015;35:548-50.

3. Wang J, Wang Y, Du X, Cui J, Wang K, Zhang L, et al. Rapid transmission of multidrug-resistant Corynebacterium striatum among susceptible patients in a tertiary hospital in China. J Infect Dev Ctries. 2016;10:1299-305.

4. Ramos JN, Valadão TB, Baio PVP, Mattos-Guaraldi AL, Vieira W. Novel mutations in the QRDR region gyrA in multidrug-resistance Corynebacterium spp. Isolates from intraveneous sites. Antonie Van Leeuwenhoek. 2020;113:589-92.

5. Sierra JM, Martinez-Martinez L, Vázquez F, Giralt E, Vila J. Relationship between mutations in the gryA gene nd quinolone resistance in clinical isolates of Corynebacterium striatum and Corynebacterium amycolatum. Antimicrob Agents Chemother. 2005;49:1714-9.

6. Wang X, Zhou H, Chen D, Du P, Lan R, Qiu X, et al. Whole-Genome Sequencing Reveals a Prolonged and Persistent Intrahospital Transmission of Corynebacterium striatum an Emerging Multidrug-Resistant Pathogen. J Clin Microbiol. 2019;57:e00683-e719.

7. Wang X, Zhou H, Du P, Lan R, Chen D, Dong A, et al. Genomic epidemiology of Corynebacterium striatum from three regions of China: an emerging national nosocomial epidemic. J Hosp Infect. 2020. https://doi.org/10 1016/j.jhin.2020.10.005.

8. Yang P, Chen YB, Jiang SP, Shen P, Lu XY, Xiao YH. Association between the rate of fluoroquinolone-resistant gram-negative bacteria and antibiotic consumption from China based on 145 tertiary hospitals data in 2014 BMC Infect Dis. 2020;20:269.

9. Kang SJ, Choi SM, Choi JA, Choi JU, Oh TH, Kim SE, et al. Factors affecting the clinical relevance of Corynebacterium striatum isolated from blood cultures. PLoS ONE. 2018;13:e0199454.

10. Souza CD, Faria YV, Sant'Anna Lde O, Viana VG, Seabra SH, Souza MC, et al. Biofilm production by multiresistant Corynebacterium striatum associated with nosocomial outbreak. Mem Inst Oswaldo Cruz. 2015;110:242-8.

11. Iaria C, Stassi G, Costa GB, Biondo C, Gerace E, Noto A, et al. Outbreak of multi-resistant Corynebacterium striatum infection in an Italian general intensive care unit. J Hosp Infect. 2007;67:102-4.

12 Khamis A, Raoult D, La Scola B. rpoB Gene sequencing for identification of Corynebacterium species. J Clin Microbiol. 2004:42:3925-31.

13. Clinical and Laboratory Standards Institute. Methods for antimicrobial dilution and disk susceptibility testing of infrequently isolated or fastidious bacteria CLSI document M45-2A. Wayne: CLSI; 2010.
14. The European Committee on Antimicrobial Susceptibility Testing. Breakpoint tables for interpretation of MICs and zone diameters. Version 10.0. www.eucast.org. Accessed 1 Jan.

15. Tenover FC, Arbeit RD, Goering RV, Mickelsen PA, Murray BE, Persing DH et al. Interpreting chromosomal DNA restriction patterns produced by pulsed-field gel electrophoresis: criteria for bacterial strain typing. J Clin Microbiol. 1995;33:2233-9.

16. Alibi S, Ferjani A, Boukadida J, Cano ME, Fernández-Martínez M, MartínezMartínez $\mathrm{L}$, et al. Occurrence of Corynebacterium striatum as an emerging antibiotic-resistant nosocomial pathogen in a Tunisian hospital. Sci Rep. 2017;7:9704.

17 Goldner NK, Bulow C, Cho K, Wallace M, Hsu FF, Patti GJ, et al. Mechanism of high-level daptomycin resistance in Corynebacterium striatum. mSphere. 2018;3:e00371-e418.

18 Hagiya H, Kimura K, Okuno H, Hamaguchi S, Morii D, Yoshida H, et al. Bacteremia due to high-level daptomycin-resistant Corynebacterium striatum: a case report with genetic investigation. J Infect Chemother. 2019;25:906-8.

19. Goering RV. Pulsed field gel electrophoresis: a review of application and interpretation in the molecular epidemiology of infectious disease. Infect Genet Evol. 2010;10:866-75

20. Baio PV, Mota HF, Freitas AD, Gomes DL, Ramos JN, Sant'Anna LO, et al. Clonal multidrug-resistant Corynebacterium striatum within a nosocomial environment, Rio de Janeiro, Brazil. Mem Inst Oswaldo Cruz. 2013:108:23-9.

21. Leonard RB, Nowowiejski DJ, Warren JJ, Finn DJ, Coyle MB. Molecular evidence of person-to-person transmission of a pigmented strain of Corynebacterium striatum in intensive care units. J Clin Microbiol. 1994:32:164-9.

22. Brandenburg AH, van Belkum A, van Pelt C, Bruining HA, Mouton JW, Verbrugh HA. Patient-to-patient spread of a single strain of Corynebacterium striatum causing infections in a surgical intensive care unit. J Clin Microbiol. 1996:34:2089-94.

23 Souza C, Mota HF, Faria YV, Cabral FO, Oliveira DR, Sant'Anna LO, et al. Resistance to antiseptics and disinfectants of planktonic and biofilmassociated forms of Corynebacterium striatum. Microb Drug Resist. 2020;26:1546-58

\section{Publisher's Note}

Springer Nature remains neutral with regard to jurisdictional claims in published maps and institutional affiliations.
Ready to submit your research? Choose BMC and benefit from:

- fast, convenient online submission

- thorough peer review by experienced researchers in your field

- rapid publication on acceptance

- support for research data, including large and complex data types

- gold Open Access which fosters wider collaboration and increased citations

- maximum visibility for your research: over 100M website views per year

At BMC, research is always in progress.

Learn more biomedcentral.com/submissions 